\title{
ALGUMAS IMPLICAÇÕES DA REFORMA DA EDUCAÇÃO SUPERIOR SOBRE A EDUCAÇÃO PROFISSIONAL E TECNOLÓGICA: II
}

\author{
Dante Henrique Moura \\ Professor do CEFET-RN, Engenheiro eletricista, Doutor em Educação, \\ Coordenador do Núcleo de Pesquisa em Educação - NUPED/CEFET-RN. \\ dante@cefetrn.br
}

Recebido e aceito em dezembro de 2005

\begin{abstract}
RESUMO
Neste artigo, analisamos as implicações de alguns dispositivos previstos no Anteprojeto de Lei da reforma da educação superior sobre a educação profissional e tecnológica, principalmente, nos centros federais de educação tecnológica - CEFETs. O eixo central de discussão está relacionado com a necessidade de que o documento legal incorpore algumas definições específicas da esfera da educação profissional e tecnológica e das instituições que nela atuam. Após a análise das versões 1 , 2 e 3 do Anteprojeto de Lei, já divulgadas pelo MEC, concluímos que é fundamental promover algumas alterações no sentido de evitar que os CEFETs, na busca da ampliação da oferta de cursos superiores, se afastem daquela que há mais de 40 anos vem sendo sua principal base de sustentação - o oferecimento público, gratuito e com excelente qualidade de cursos técnicos de nível médio.
\end{abstract}

Palavras-chave: educação profissional; educação tecnológica; educação superior; reforma.

\section{ALGUNAS IMPLICACIONES DE LA REFORMA DE LA EDUCACIÓN SUPERIOR SOBRE LA EDUCACIÓN PROFESIONAL Y TECNOLÓGICA:II}

\section{RESUMEN}

En este artículo vamos a analizar las implicaciones de algunos mecanismos previstos en la propuesta de Proyecto de Ley de Reforma de la educación superior sobre la educación profesional y tecnológica, principalmente, en lo que concierne a los centros federales de educación tecnológica - CEFETs. El eje central de análisis está relacionado con la necesidad de que al texto legal se añadan algunas definiciones específicas de la esfera de la educación profesional y tecnológica y de las correspondientes instituciones que en ella actúan. Tras el análisis de las tres primeras propuestas del Proyecto de Ley ya divulgadas por el MEC, concluimos que es fundamental promover algunos cambios en aras de evitar que los CEFETs, en la búsqueda de ampliar sus ofertas de cursos superiores, se van alejando de aquél que es su principal dominio de trabajo desde hace más de 40 años - la oferta pública, gratuita y con excelente calidad de cursos técnicos de grado medio.

Palabras clave: educación profesional; educación tecnológica; educación superior; reforma. 


\section{ALGUMAS IMPLICAÇÕES DA REFORMA DA EDUCAÇÃO SUPERIOR SOBRE A EDUCAÇÃO PROFISSIONAL E TECNOLÓGICA: II}

\section{Delimitando o objeto de análise}

Neste trabalho, analisamos as implicações de alguns dispositivos previstos no Anteprojeto de Lei da reforma da educação superior ${ }^{1}$ sobre a educação profissional e tecnológica.

O eixo central de discussão e argumentação está relacionado com a necessidade de que a proposta em discussão incorpore claramente algumas definições específicas da esfera da educação profissional e tecnológica e das instituições que nela atuam.

(disponível

Queremos ressaltar que logo após a publicação da primeira versão do Anteprojeto de Lei http://www.mec.gov.br/reforma/Documentos/DOCUMENTOS/2004.12.6.16.20.53.pdf)

escrevemos o texto Algumas implicações da reforma da educação superior sobre a educação profissional e tecnológica, no qual fizemos uma análise semelhante à atual, ou seja, discutimos a necessidade do documento legal tratar das especificidades das instituições que atuam na educação tecnológica. Naquela versão eram os artigos 13, 15 e 27 que tratavam das universidades, centros universitários e faculdades, respectivamente, sem fazerem nenhuma referência específica à vertente da educação tecnológica.

A

segunda

versão

(disponível

em

http://www.mec.gov.br/reforma/Documentos/DOCUMENTOS/2005.7.1.13.14.17.pdf), no $\S 2^{\circ}$ do artigo 18 e $\S 2^{\circ}$ do artigo 23, confere tratamento específico às universidades e centros universitários tecnológicos, contemplando, dessa forma, as observações que fizemos no mencionado artigo e amplas discussões que ocorreram no próprio MEC, principalmente, no âmbito da Secretaria de Educação Profissional e Tecnológica - SETEC.

Por outro lado, a terceira versão publicada em 29/07/2005² (disponível em http://www.mec.gov.br/reforma/Documentos/DOCUMENTOS/2005.8.2.21.24.4.pdf), volta a não especificar o segmento da educação tecnológica em seus artigos 18, 22 e 24 (que tratam das universidades, centros universitários e faculdades, respectivamente), sendo necessário, portanto, resgatar as discussões, estudos e análises que resultaram nas modificações contempladas na segunda versão, as quais não permaneceram no atual documento.

Além dessas considerações, também é importante esclarecer que o trabalho não tem o objetivo de apresentar uma visão definitiva e fechada sobre o Anteprojeto de Lei como um todo, nem sobre as questões aqui tratadas de forma mais específica. Ao contrário, pretendemos contribuir para o estabelecimento de um debate em torno da temática, a fim de que se construa uma solução duradoura e coerente com as verdadeiras necessidades educacionais da sociedade brasileira.

O artigo foi dividido em quatro seções: nesta primeira, buscamos dar uma visão geral sobre o trabalho; na segunda, analisamos alguns aspectos que limitam os horizontes da discussão do Anteprojeto de Lei de reforma da educação superior; em seguida, fazemos uma breve análise da situação atual da educação profissional e tecnológica nas redes pública e privada; e, na última, discutimos as repercussões do atual anteprojeto de Lei de reforma da educação superior sobre a educação tecnológica e propomos algumas alterações nesse dispositivo.

\footnotetext{
1 Estamos nos referindo à $3^{\text {a }}$ versão, publicada em 29/07/2005 e disponível em http://portal.mec.gov.br/arquivos/pdf/anteprojeto.pdf.

${ }^{2}$ No momento em que escrevemos este texto (novembro de 2005), esta terceira versão tramita no poder executivo e as informações disponíveis são de que está prestes a ser encaminhada ao Congresso Nacional
} 


\title{
2. Alguns aspectos que limitam o horizonte da discussão sobre a reforma da educação superior brasileira
}

Nesta seção, vamos refletir, ainda que de forma não exaustiva, sobre alguns elementos que estabelecem limites à atual discussão acerca da reforma da educação superior do Brasil.

O primeiro deles é a falta de uma clareza maior sobre o modelo de desenvolvimento socioeconômico do país (MOURA, 2004e). O modelo vigente, produto da dependência econômica externa histórica do país ${ }^{3}$, é baseado, nas exportações agroindustrial, agropecuária e de matérias primas e na importação acrítica das tecnologias produzidas nos países de capitalismo avançado. Isso, ao longo do tempo, vem fazendo com que o país não tenha um modelo próprio de desenvolvimento orientado às suas necessidades econômicas e melhorias sociais. Ao invés disso, vem prevalecendo historicamente a submissão aos indicadores econômicos ditados desde fora, aos organismos internacionais de financiamento e aos investidores internacionais, principalmente os de curto prazo.

Com a consolidação do modelo de sociedade neoliberal, apoiada na globalização dos mercados (ANDERSON, 1996), a qual, por sua vez, é viabilizada e potencializada pelos avanços tecnológicos, principalmente, pelas chamadas tecnologias da informação e da comunicação - TIC, essa situação se agrava a passos mais largos, de modo que a distância entre os incluídos e os excluídos aumenta cada vez mais.

Infelizmente, esse cenário é coerente com a lógica do mercado global. Esses coletivos excluídos constituem a "população precária" (DIETERICH, 1999; MOURA, 2004d). Esta população tem um papel relevante ao constituir-se em um exército de reserva e contribuir para exercer uma constante pressão de baixa sobre os salários dos que têm emprego e funcionar como armazém humano para equilibrar as oscilações conjunturais da demanda de "mão de obra".

Apesar dessa dura realidade, existe outro tipo de sociedade que pode ser buscada. Uma sociedade que tenha o ser humano e suas relações com o meio-ambiente e a natureza em geral como centro e na qual a tecnologia esteja submetida a uma racionalidade ética no lugar de estar a serviço exclusivo do mercado e do fortalecimento dos indicadores econômicos. Nessa sociedade, a construção do conhecimento deve estar voltada para a busca de soluções aos problemas das pessoas e das comunidades menos favorecidas na perspectiva da edificação de uma sociedade socialmente justa (MOURA, 2003a; 2003b).

Nessa sociedade, o homem deve ser concebido como um ser integral, "o qual, no confronto com outros sujeitos, afirma a sua identidade social e política, e reconhece a identidade de seus semelhantes, ambas construídas nos processos de desenvolvimento da individualização e da intersubjetividade” (CEFET-RN, 1999, p. 47). Essa concepção de homem resulta em pensar um "eu” socialmente competente, um sujeito político, um cidadão

\begin{abstract}
que busca a autonomia, a auto-realização e a emancipação através de sua participação responsável e crítica nas esferas sócio-econômico-políticas. Isto consiste em perceber o homem como um ser capaz de colocar-se diante da realidade histórica para, entre outros aspectos, reagir à coerção da sociedade, questionar as pretensões de validade e de normas sociais, construir uma unidade de interesses e descobrir novas estratégias de atuação solidária (CEFET-RN, 1999, p.47).
\end{abstract}

Esta concepção de homem é mais ampla do que a requerida pela lógica da globalização econômica, de forma que os processos educativos estruturados a partir desse referencial deverão

\footnotetext{
${ }^{3}$ Como este não é o tema central deste artigo, sugiro ver alguns trabalhos que tratam essa questão de forma mais profunda: FREITAG (1979); FURTADO (1992); CHOMSKY; DIETERICH (1999), só para citar alguns exemplos.
} 
contribuir para a formação de profissionais-cidadãos capazes de participar politicamente na sociedade, atuando como sujeitos nas esferas pública, privada e no terceiro setor, espaços privilegiados da prática cidadã, em função de transformações que apontem na direção dessa sociedade mais justa e igualitária.

Entretanto, a opção por esse modelo alternativo de desenvolvimento socioeconômico não ocorreu no Brasil. Essa falta de definição, além das implicações já mencionadas, também contribui para outro fator limitante na busca de um modelo para a educação do país: a fragmentação das discussões dos grandes temas da agenda educacional. Por isso, está-se discutindo de forma separada a reforma da educação superior, um anteprojeto de Lei Orgânica da educação profissional e tecnológica, além de novos parâmetros curriculares para a educação básica. Na verdade, a mudança mais ampla e que incorporaria todas as ações parciais seria a da própria Lei de Diretrizes e Bases da Educação Nacional - LDBEN, cujo caráter minimalista está viabilizando o aprofundamento do processo de mercantilização da educação (FRIGOTTO, 2001).

Contudo, a atual correlação de forças políticas instaladas no centro do poder político do país não nos fornece indicadores de que um amplo processo de (re)discussão da LDBEN nos conduziria a uma Lei comprometida com a educação pública e, em conseqüência, com a busca de uma sociedade justa socialmente. Essa discussão teria que enfrentar a problemática educação pública versus educação privada, em todos os níveis, na perspectiva da opção pelo fortalecimento da educação pública, gratuita e de qualidade. Infelizmente, reafirmamos, que o cenário político configurado pela atual correlação de forças não nos permite ser ingênuos a ponto de pensar que a reabertura dessa discussão nos levaria à direção almejada por aqueles que buscamos uma sociedade cujo modelo de desenvolvimento socioeconômico não seja ditado, quase exclusivamente, pelos interesses do mercado.

Um aspecto que ratifica o pensamento apresentado acima é o fato de que na impossibilidade de atacar a raiz da questão, o que, desde o ponto de vista educativo seria promover o fortalecimento e ampliação da educação superior pública, o Anteprojeto de Lei trata de definir uma função social para as instituições de educação superior privadas. Entretanto, os que acompanhamos este processo, já vimos as reações exacerbadas daqueles que representam as empresas comerciais que atuam na educação superior. Isso ocorre porque se está aflorando a incompatibilidade entre os fins educacionais que efetivamente têm uma função social e os objetivos do mercado que, evidentemente, visa à acumulação do capital através da venda de cursos/diplomas à maioria da população que, por várias razões, não tem acesso às instituições públicas de educação superior.

Diante desse quadro, já que não há condições políticas objetivas para que se realize essa discussão mais ampla, vamos restringi-la ao âmbito da reforma da educação superior e suas implicações sobre a educação profissional e tecnológica, embora não possamos perder de vista 0 macrocontexto delineado.

\section{A educação tecnológica nas instituições públicas e privadas}

Após traçar o macropanorama onde está inserida a reforma da educação superior brasileira é necessário caminhar na direção de nosso objeto central de discussão: suas implicações sobre a educação profissional e tecnológica.

Antes, porém, precisamos evidenciar a verdadeira confusão terminológica que há em torno desse segmento da educação nacional. Transita-se entre termos como formação profissional, educação profissional, educação tecnológica e, mais recentemente, educação profissional e tecnológica sem uma maior precisão sobre o significado que carrega cada um deles. Entretanto, como este não é nosso objeto de estudo neste trabalho, vamos, a partir de agora, utilizar a expressão 
educação tecnológica, exclusivamente, para facilitar o entendimento do leitor, uma vez que essa é a expressão utilizada ao longo do Anteprojeto de Lei de reforma da educação superior.

Igualmente, também necessitamos localizar o leitor, ainda que de forma muito breve, sobre o cruzamento dos caminhos da educação tecnológica e da educação superior.

Por um lado, no âmbito das universidades públicas essas ofertas educacionais surgiram, nos anos 70 e 80, através dos cursos de formação de tecnólogos, com menor duração que os cursos denominados plenos, e voltados para uma formação superior mais direcionada para as necessidades imediatas do setor produtivo. Esses cursos, em seu formato inicial, não tiveram vida longa no sistema das universidades públicas brasileiras, salvo raras exceções ${ }^{4}$.

Por outro lado, algumas escolas técnicas federais transformadas em centros federais de educação tecnológica ${ }^{5}$ no final dos anos 70 também passaram a atuar na formação de tecnólogos. Além disso, alguns sistemas de educação profissional dos estados, principalmente a rede Paula Souza, em São Paulo, também começaram a oferecer cursos de formação de tecnólogos.

Posteriormente, outras duas escolas técnicas foram transformadas em CEFETs no início dos anos 90, a do Maranhão e a da Bahia, as quais também passaram a atuar na formação de tecnólogos. A transformação das demais escolas técnicas em CEFETs ocorreu a partir de 1994 com a promulgação da Lei ${ }^{0}$ 8.948. Dessa forma, de 1994 aos dias atuais, as antigas escolas técnicas e algumas escolas agrotécnicas federais foram transformadas em CEFETs e também oferecem cursos superiores de tecnologia.

Paralelamente, na iniciativa privada, o grande avanço na oferta desses cursos aconteceu a partir da nova LDBEN, de 1996, e do Decreto $n^{0}$ 2.208/1997. Este Decreto e pareceres posteriores do Conselho Nacional de Educação foram fundamentais para consolidar os cursos superiores de tecnologia no âmbito da educação superior brasileira, porque os definiram claramente como cursos de graduação e, portanto, que quem os conclui goza das mesmas prerrogativas de outros graduados desde o ponto de vista formal, inclusive o direito à continuidade de estudos através de cursos de pós-graduação lato sensu e stricto sensu.

É necessário ainda resgatar outras importantes diferenças na gênese desses cursos nos âmbitos privado e público, particularmente nos centros federais de educação tecnológica.

Nos CEFETs, os cursos superiores de tecnologia nasceram sob a perspectiva da verticalização da educação tecnológica, ou seja, a criação de cursos superiores dentro das áreas em que essas instituições atuavam historicamente na formação de técnicos de nível médio. Dessa forma, vem se ampliando na rede dos CEFETs distribuída ao longo da geografia do país a possibilidade do estudante entrar em uma instituição para fazer seus estudos do ensino médio/formação profissional técnica de nível médio e, posteriormente, ir diretamente ao mundo do trabalho ou seguir uma carreira de nível superior na mesma instituição e na mesma área em que estudou a formação profissional técnica ou, ainda, fazer as duas coisas ao mesmo tempo, ou seja, ir ao mundo do trabalho e, paralelamente, fazer a sua carreira universitária, geralmente à noite, em uma instituição pública, gratuita de qualidade e na qual ele já sabe transitar.

Esse é um modelo que apesar de ainda estar em construção, já apresenta bons resultados, pois a cada dia cresce a busca por seus cursos e os resultados tanto de inserção no mundo do

\footnotetext{
${ }^{4}$ Há uma análise crítica muito rigorosa com relação a essa experiência com a qual estamos de acordo em muitos aspectos, entretanto não vamos nos aprofundar nessa análise em função do objetivo central deste artigo.

${ }^{5}$ Escolas técnicas federais do Paraná (atual CEFET-PR), do Rio de Janeiro (atual CEFET-RJ) e de Minas Gerais (atual CEFET-MG).
} 
trabalho como de continuidade de estudos em nível de pós-graduação estão avançando em todo o país.

Alguns fatores importantes potencializam esse modelo e a qualidade de suas ofertas. Do ponto de vista pedagógico, tem-se constatado, ao longo do tempo, que os alunos que ingressam no ensino superior provenientes de uma carreira técnica de nível médio, principalmente na mesma área, apresentam maior facilidade para desenvolver-se no curso do que aqueles provenientes do ensino médio propedêutico, independentemente dessa carreira de nível superior ser um curso de graduação tecnológica ou uma carreira tradicional da educação superior.

Esse fato é facilmente constatável nos cursos de engenharia oferecidos pelas universidades federais, os quais recebem grandes contingentes de alunos oriundos das antigas escolas técnicas, atuais CEFETs. Esses alunos, geralmente se destacam em relação aos demais. Esse fenômeno é observado em todo o país, porém ainda é mais acentuado nas regiões mais afastadas do eixo sulsudeste, ou seja, nas regiões em que as escolas técnicas, CEFETs e agrotécnicas federais, têm uma dimensão maior, proporcionalmente à oferta educacional dos respectivos estados.

Outro aspecto muito importante a considerar é a infraestrutura, tanto do ponto de vista de instalações físicas, incluindo, prédios, laboratórios, equipamentos, salas de aulas teóricas e demais recursos, como o pessoal, tanto docente como técnico-administrativo. O que acontece é que se utiliza toda essa infra-estrutura de forma otimizada, pois, nessas instituições, atende-se ao mesmo tempo os cursos técnicos e os cursos superiores de graduação tecnológica, além de outras ofertas educacionais.

Assim sendo, é importante destacar que o pessoal docente da rede federal de educação tecnológica vem se constituindo em um quadro altamente especializado dentro do país, pois na maioria dos atuais CEFETs, os profissionais começaram a atuar na formação de técnicos de nível médio e a partir da entrada das respectivas instituições na educação superior, vêm capacitando-se em nível de mestrado e doutorado nas mais diversas áreas do conhecimento, em universidades nacionais e estrangeiras. Dessa forma, atuam na formação técnica de nível médio, nos cursos de graduação tecnológica, nas licenciaturas e, em alguns casos, na pós-graduação, associando teoria e prática em cada um desses níveis.

Apesar dessas vantagens, é muito importante cuidar para que não haja uma distorção nessa verticalização técnico-tecnológico. Trata-se da possibilidade do aumento da oferta dos cursos superiores de tecnologia em detrimento da oferta dos cursos técnicos. Esse é um problema crucial e que não pode ser visto apenas a partir da ótica interna dos que atuam nos CEFETs, mas sim a partir das necessidades da sociedade brasileira. Dessa forma, qualquer política voltada para a educação tecnológica tem que garantir a continuidade da oferta dos cursos técnicos como prioritária e, além disso, apontar para a sua ampliação.

Isso é fundamental porque a sociedade e o mundo do trabalho geram muito mais postos de trabalho de nível intermediário do que de nível superior. Evidentemente, não queremos aqui advogar que as pessoas não possam ter a oportunidade de acesso a estudos universitários. Ao contrário, é fundamental ampliar a oferta pública de educação superior, entretanto, não podemos fechar os olhos à realidade que nos diz que os empregados de nível superior correspondem a menos da metade daqueles de nível intermediário e menos de $16 \%$ do total de empregados ${ }^{6}$ e que, além disso, não há tendência de reversão desse quadro no curto e médio prazos.

Diante desse contexto, é papel fundamental da rede federal de educação tecnológica continuar oferecendo os cursos técnicos e superiores de tecnologia ao mesmo tempo, tendo como referência a verticalização da educação tecnológica e a ampliação dessas ofertas, mantendo um maior número de vagas nos cursos técnicos.

\footnotetext{
${ }^{6}$ Fonte MTE/RAIZ 2000.
} 
Com relação à verticalização, desde o Decreto $n^{0}$ 2.208/1997 que a questão é tratada da forma como aqui propomos. Assim, aquele instrumento legal já definia três níveis para a educação profissional: básico, técnico e tecnológico. Posteriormente, a legislação que o sucedeu também continuou na mesma direção, ou seja, o Decreto $n^{0} 5.154 / 2004$, em seu artigo $1^{0}$, define que a educação profissional será desenvolvida por meio de cursos e programas de:

I - Formação inicial e continuada de trabalhadores;

II - Educação profissional técnica de nível médio; e

III - Educação profissional tecnológica de graduação e de pós-graduação.

Dessa forma, está muito clara a intenção política de que as instituições que atuam na educação tecnológica, que são as mesmas que oferecem a educação profissional, trabalhem de forma articulada nessas ofertas educacionais.

Além disso, o Decreto $n^{\circ}$ 5.154/2004 também estabelece como objetivos dos CEFETs, entre outros:

- Ministrar cursos de formação inicial e continuada de trabalhadores, incluídos a iniciação, o aperfeiçoamento e a atualização, em todos os níveis e modalidades de ensino;

- Ministrar educação de jovens e adultos, contemplando os princípios e práticas inerentes à educação profissional e tecnológica;

- Ministrar ensino médio, observada a demanda local e regional e as estratégias de articulação com a educação profissional técnica de nível médio;

- Ministrar educação profissional técnica de nível médio, de forma articulada com o ensino médio, destinada a proporcionar habilitação profissional para os diferentes setores da economia (grifo nosso);

- Ministrar ensino superior de graduação e de pós-graduação lato sensu e stricto sensu, visando à formação de profissionais e especialistas na área tecnológica (grifo nosso);

- Ofertar educação continuada, por diferentes mecanismos, visando à atualização, ao aperfeiçoamento e à especialização de profissionais na área tecnológica.

Como se vê, a oferta de cursos técnicos de nível médio e de cursos de graduação tecnológica é algo intrínseco à existência dos CEFETs e, além disso, são atividades estratégicas para a educação nacional.

Com relação às instituições privadas que oferecem cursos superiores de tecnologia, salvo poucas exceções - caso do sistema S, não houve a verticalização a partir de cursos técnicos. Dessa forma, perderam-se as duas principais vantagens que mencionamos ao relatar o surgimento desses cursos no âmbito das escolas técnicas, CEFETs e agrotécnicas federais: as questões pedagógicas e da infraestrutura física e de recursos humanos compartilhada. Essa diferença ocorreu e continua acontecendo porque a lógica que levou a maioria das empresas privadas de educação a atuar nesse campo foi a de mercado, ao invés da qualidade educacional das ofertas e a responsabilidade social.

A lógica de mercado é perfeitamente identificável quando se alardeia em todo o país campanhas publicitárias do tipo "empresa educativa tal" oferece formação em nível superior em apenas 2 anos, com uma mensalidade de unicamente " $x$ " reais. Evidentemente, em um país onde 
prevalece a cultura de que a formação em nível superior abre as portas para uma vida melhor economicamente, o que efetivamente é um engano à população ${ }^{7}$; onde a oferta pública de educação superior está quase estagnada por falta de investimentos; e onde há uma campanha orquestrada contra tudo o que é público, um chamamento dessa natureza é extremamente atrativo. Dessa forma, houve um aumento significativo da oferta de cursos superiores de tecnologia em todo o país nessas empresas comerciais. Entretanto, as avaliações realizadas pelo MEC estão identificando a precariedade de grande parte delas.

Diante desses fatos, é fundamental que a reforma da educação superior defina claramente o que é a educação tecnológica e as condições em que as instituições educacionais devem nela atuar.

\section{A educação tecnológica e a reforma da educação superior}

Após a discussão realizada ao longo das demais seções deste trabalho, principalmente na anterior, vimos propor algumas adequações no Anteprojeto de Lei de reforma da educação superior no que se refere à educação tecnológica e às instituições que nela atuam. Isso não significa que este Anteprojeto não nos provoque outras inquietações, entretanto, neste momento, optamos por abordar apenas as questões mais diretamente relacionadas com a educação tecnológica.

Em primeiro lugar, é fundamental definir que as instituições que atuam nessa esfera devem fazê-lo de forma verticalizada (MOURA, 2004c) para garantir a qualidade das ofertas educacionais e a continuidade dos cursos técnicos de nível médio.

Dessa forma, propomos a alteração dos artigos do Anteprojeto de Lei que categorizam as instituições de educação superior em universidades, centros universitários e faculdades para incluir as especificidades das instituições que atuam ou pretendem atuar no campo específico da educação tecnológica. Ou seja, é fundamental explicitar que para ser considerada universidade tecnológica, centro universitário tecnológico ou faculdade tecnológica a instituição atue de forma verticalizada nas respectivas áreas em que oferece cursos superiores de tecnologia (artigos 18, 22 e 24).

Essa mesma alteração, a título de reforço, precisa ser introduzida nos artigos que tratam especificamente das instituições federais de educação (Capítulo I do Título II). Dessa forma, é neecssário que o documento mencione que as universidades, centros universitários e faculdades federais especializadas em educação tecnológica devem ofertar, obrigatoriamente, cursos técnicos de nível médio nas respectivas áreas de formação profissional em que atuam.

Essas modificações se fazem necessárias porque os artigos mencionados anteriormente estabelecem regras gerais para classificar as instituições de educação superior como faculdades, centros universitários e universidades. Essas regras gerais propostas levam em consideração a quantidade, diversidade, os diferentes níveis de atuação e a qualidade dos cursos oferecidos para que uma instituição mude seu status de faculdade para centro universitário e desse para o de universidade.

As diretrizes são muito claras, entretanto não dão conta das especificidades das instituições que atuam na educação tecnológica, de modo que aplicá-las tal e como estão postas tenderia a produzir o afastamento da oferta de cursos técnicos daquelas instituições que já atuam de forma verticalizada - caso dos CEFETs, já que para mudar de status de faculdade tecnológica para centro universitário tecnológico ou desse para universidade tecnológica não se levaria em consideração todo o esforço e capacidade institucionais que viabilizam o oferecimento dos cursos técnicos.

\footnotetext{
${ }^{7}$ Esta é uma discussão que merece um maior aprofundamento, mas não vamos tratá-la aqui, pois não se trata do objetivo central do estudo.
} 
Dessa forma, ao longo do tempo essa oferta deixaria de ser prioritária, por não ser considerada quando a instituição pleiteasse uma mudança de status.

Esse afastamento dos CEFETs da oferta de cursos técnicos de nível médio produziria efeitos nefastos para a educação e para a sociedade brasileira, tendo em vista que esse é o conjunto de instituições que reconhecidamente atua com elevada qualidade na formação técnica (MOURA, 2002). Para ilustrar essa afirmação basta olhar o quadro de pessoal de importantes empresas nacionais públicas e privadas para constatar que grande parte do contingente de seus trabalhadores foram (e continuam sendo) formados nos cursos técnicos oferecidos por essas instituições.

Nessa perspectiva, podemos citar a PETROBRAS, a companhia Vale do Rio Doce, as inúmeras concessionárias de energia elétrica, de serviços de águas e saneamento, de telefonia, entre muitos outros setores da economia nacional. Além disso, também é muito considerável o número de médias e pequenas empresas que absorvem os técnicos egressos da rede de CEFETs e, igualmente, significativa, é a quantidade de médios e pequenos empreendedores oriundos dos cursos técnicos.

Por outro lado, atualmente, a matrícula total de técnicos de nível médio no país, além de muito pequena comparativamente à matrícula do ensino médio é maior na iniciativa privada (58,02\%) do que nos sistemas públicos (41,98\%), conforme evidenciado a seguir na Tabela 1.

Tabela 1 - Matrícula no ensino médio e na educação profissional técnica de nível médio no Brasil por dependência administrativa.

\begin{tabular}{|c|c|c|c|c|c|}
\hline \multirow{2}{*}{$\begin{array}{c}\text { Dependência } \\
\text { administrativa }\end{array}$} & \multirow{2}{*}{$\begin{array}{c}\text { Ensino } \\
\text { Médio } \\
\text { (Regular) }\end{array}$} & \multicolumn{2}{|c|}{$\begin{array}{ll}\text { Ensino Médio } & \text { (EJA) }\end{array}$} & \multirow{2}{*}{$\begin{array}{l}\text { Ensino Médio } \\
\text { (TOTAL) }\end{array}$} & \multirow{2}{*}{$\begin{array}{c}\text { Educação } \\
\text { Profissional - } \\
\text { Nível técnico }\end{array}$} \\
\hline & & Presencial & $\begin{array}{c}\text { Semi- } \\
\text { presencial }\end{array}$ & & \\
\hline Brasil & 9.169 .357 & 1.157 .593 & 551.460 & 10.878 .410 & 676.093 \\
\hline Federal & 67.652 & 316 & 0 & 67.968 & 82.293 \\
\hline Estadual & 7.800 .983 & 950.536 & 497.306 & 9.248 .825 & 179.456 \\
\hline Municipal & 189.331 & 37.894 & 17.993 & 245.218 & 21.642 \\
\hline Privada & 1.111 .391 & 168.847 & 36.161 & 1.316 .399 & 392.702 \\
\hline
\end{tabular}

Fonte: elaboração nossa, a partir do Censo Escolar 2004.

Ao analisar a Tabela 1 percebemos que a oferta de cursos técnicos de nível médio corresponde a apenas a 6,21\% da oferta total do ensino médio. Além disso, a oferta no âmbito federal corresponde a parcos $21,7 \%$ do total de matrículas dos cursos técnicos de nível médio.

Diante do exposto, se não houver a mudança proposta nesse Anteprojeto de Lei, poderemos estar construindo um caminho que tende a deixar à mercê exclusivamente das empresas privadas que atuam no mercado educacional uma área estratégica de formação de quadros qualificados e, na mesma situação, o público que historicamente é atendido pela rede federal de educação tecnológica e que através da formação proporcionada por essas instituições consegue inserir-se na sociedade e no mundo trabalho, passando a serem sujeitos de suas próprias vidas. A responsabilidade social dos CEFETs não deverá permitir que isso ocorra.

\section{Considerações finais}

Ante todo o exposto é forçoso constatar que, caso não se concretizem alterações na linha do aqui proposto, a própria estrutura da Secretaria de Educação Profissional e Tecnológica - SETEC estará fortemente ameaçada, uma vez que a ação central dessa secretaria está vinculada aos CEFETs. 
Ora, se gradativamente essas instituições passarem a buscar a elevação de seus status na direção de alcançar a condição de universidade tecnológica e, para isso, tenderem a diminuir ou até eliminar a oferta de cursos técnicos, como já vem ocorrendo nos últimos anos em alguns casos, qual seria o papel da SETEC nesse novo contexto? Não nos é muito difícil imaginar que a concreção desse cenário conduziria ao seu esvaziamento e, portanto, se lhe atribuiria outro papel ou simplesmente se encerrariam suas atividades. Resta aos que atuamos nesse segmento educacional decidirmos se é esse o caminho que pretendemos trilhar.

Além disso, a ausência dos dispositivos sugeridos também estaria contribuindo para a continuidade da situação atual no âmbito das organizações privadas que atuam na educação tecnológica. Essas empresas priorizam a atuação nos cursos superiores de tecnologia em detrimento da oferta de cursos técnicos. Isso ocorre porque do ponto de vista do mercado, lógica que orienta a ação dessas organizações, é melhor oferecer o produto "curso superior de tecnologia" do que "curso técnico de nível médio”, principalmente nas áreas em que são exigidos investimentos significativos em equipamentos e laboratórios mais sofisticados.

Assim sendo, concluímos afirmando que é fundamental promover essas alterações sob pena de estarmos assistindo passivamente ao afastamento dos CEFETs daquela que há mais de 40 anos vem sendo sua principal base de sustentação - a oferta pública, gratuita e com excelente qualidade de cursos técnicos de nível médio, o que já transformou e continua transformando a vida de inúmeros jovens, principalmente, aqueles provenientes das classes menos favorecidas (MOURA, 2000; 2004a), além de contribuir significativamente para desenvolvimento econômico do país.

\section{Referências}

ANDERSON, P. Balanço do neoliberalismo. In: SADER, E.; GENTILI, P. (Orgs.). Pósneoliberalismo. As políticas sociais e o estado democrático. 3 Ed.. Rio de Janeiro: Paz e Terra, 1996, p. 9-23.

BRASIL. Ministério da Educação. Anteprojeto de Lei de reforma da educação superior $-\mathbf{1}^{\text {a }}$ versão. Disponível em http://www.mec.gov.br/reforma/Documentos/DOCUMENTOS/2004.12.6.16.20.53.pdf . Acesso em 12/12/2004.

BRASIL. Ministério da Educação. Anteprojeto de Lei de reforma da educação superior $-2^{\text {a }}$ versão. Disponível em http://www.mec.gov.br/reforma/Documentos/DOCUMENTOS/2005.7.1.13.14.17.pdf. Acesso em $13 / 06 / 2005$.

BRASIL. Ministério da Educação. Anteprojeto de Lei de reforma da educação superior - $3^{\text {a }}$ versão. Disponível em http://www.mec.gov.br/reforma/Documentos/DOCUMENTOS/2005.8.2.21.24.4.pdf. Acesso em $\underline{17 / 08 / 2005}$.

CENTRO FEDERAL DE EDUCAÇÃO TECNOLÓGICA DO RIO GRANDE DO NORTE. Projeto de reestruturação curricular. Natal: CEFET-RN,1999.

DIETERICH, H. Globalización, educación y democracia. In: La Aldea global. Txalaparta. Tafalla / Argentina, 1999.

FRIGOTTO, G. Mudanças societárias e as questões educacionais da atualidade no Brasil. Arquivo eletrônico, 2001.

FURTADO, C. Brasil: a construção interrompida. São Paulo: Paz e terra, 1998. 
MOURA, D. H. La gestión socialmente productiva de instituciones de educación para el trabajo. In: Actas de las V Jornadas Andaluzas de Organización de Instituciones Educativas. Vol III. Granada: serviço de publicações da Universidade de Granada, 2000.

. La educación profesional en Brasil. In: Revista Diálogos, Barcelona, ano VIII, Volume 2/2002, 2002.

. Educação profissional: desafios e perspectivas. In: Profissionalização: alternativa para o desenvolvimento e a cidadania, Brasília, Boletim do MEC, nov/2003a.

. La Autoevaluación como Instrumento de Mejora de Calidad: un Estudio de Caso (El Centro Federal de Educação Tecnológica do Rio Grande do Norte / CEFET - RN / Brasil). 2003. 516 f. Tese (Doutorado em educação) - Faculdade de Educação da Universidade Complutense de Madri. Madri, 2003b.

A gestão socialmente produtiva de instituições de educação profissional In: $\mathbf{1}^{\mathbf{0}}$ Encontro Internacional de Turismo, Hospitalidade e Desenvolvimento Sustentável. CEFET-RN: Natal, 2004a.

La gestión socialmente productiva de instituciones de educación profesional y tecnológica In: IV Encuentro Europa-América Latina sobre formación y cooperación profesional y tecnológica. Islas de Margaritas: no prelo, 2004b.

El nivel básico de la educación profesional: análisis y discusión de algunos elementos en el contexto brasileño y en el CEFET-RN en particular. In: IV Encuentro Europa-América Latina sobre formación y cooperación profesional y tecnológica. Islas de Margaritas: no prelo, 2004c.

Sociedade, educação, tecnologia e os usos das TIC nos processos educativos. In: Trabalho necessário. Revista Eletrônica do neddate. Disponível em http://www.uff.br/trabalhonecessario/. Acesso em 30/10/2004, 2004d.

. Formação e capacitação dos profissionais da educação profissional e tecnológica orientada a uma atuação socialmente produtiva. In: III Seminário regional para discussão da proposta de Anteprojeto de Lei Orgânica para a EPT. Natal: disponível em http://mec.gov.br. Acesso 12/12/2004, 2004e. 